\title{
Protein Profiles Associated with Anoikis Resistance of Metastatic MDA-MB-231 Breast Cancer Cells
}

\author{
Chareeporn Akekawatchai ${ }^{1 *}$, Sittiruk Roytrakul ${ }^{2}$, Suthathip Kittisenachai ${ }^{2}$, \\ Patcharee Isarankura-Na-Ayudhya $^{1}$, Sarawut Jitrapakdee ${ }^{3}$
}

\begin{abstract}
Resistance to anoikis, a cell-detachment induced apoptosis, is one of the malignant phenotypes which support tumor metastasis. Molecular mechanisms underlying the establishment of this phenotype require further investigation. This study aimed at exploring protein expression profiles associated with anoikis resistance of a metastatic breast cancer cell. Cell survival of suspension cultures of non-metastatic MCF-7 and metastatic MDA-MB-231 cells were compared with their adherent cultures. Trypan blue exclusion assays demonstrated a significantly higher percentage of viable cells in MDA-MB-231 than MCF-7 cell cultures, consistent with analysis of annexin V-7-AAD stained cells indicating that MDA-MB-231 possess anti-apoptotic ability 1.7 fold higher than MCF-7 cells. GeLC-MS/MS analysis of protein lysates of MDA-MB-231 and MCF-7 cells grown under both culture conditions identified 925 proteins which are differentially expressed, 54 of which were expressed only in suspended and adherent MDA-MB-231 but not in MCF-7 cells. These proteins have been implicated in various cellular processes, including DNA replication and repair, transcription, translation, protein modification, cytoskeleton, transport and cell signaling. Analysis based on the STITCH database predicted the interaction of phospholipases, PLC and PLD, and 14-3-3 beta/alpha, YWHAB, with the intrinsic and extrinsic apoptotic signaling network, suggesting putative roles in controlling anti-anoikis ability. MDA-MB-231 cells grown in the presence of inhibitors of phospholipase C, U73122, and phospholipase D, FIPI, demonstrated reduced ability to survive in suspension culture, indicating functional roles of PLC and PLD in the process of anti-anoikis. Our study identified intracellular mediators potentially associated with establishment of anoikis resistance of metastatic cells. These proteins require further clarification as prognostic and therapeutic targets for advanced breast cancer.
\end{abstract}

Keywords: Anoikis resistance - MDA-MB-231 - MCF-7 - proteomics - GeLC-MS/MS - STITCH

Asian Pac J Cancer Prev, 17 (2), 581-590

\section{Introduction}

Metastasis and invasion are major causes of death from cancers. They are multi-step processes including dissociation of cancer cells from a primary site, survival in the circulatory and lymphatic systems, and colonization in the distant organs. Generally, an epithelial or endothelial cell undergoes a particular type of apoptosis, termed anoikis, in the absence of attachment to extracellular matrix (ECM) or neighboring cells. Cancer cells acquire anoikis resistance to survive after the detachment from ECM and metastasizes to the target organs (Paoli et al., 2013). Previous studies have shown that an acquisition of anoikis resistance is a critical prerequisite for cancer metastasis, and there is a link between an anchorageindependent growth and survival of circulatory tumor cells, and metastatic ability of the cells in orthotopic cancer models (Glinskii et al., 2003; Kim et al., 2012; Malin et al., 2015). The molecular and functional analyses of anokis resistant cancer cells are essential for the understanding of the cellular basis of cancer metastasis and invasion.

Growing evidence have indicated that cancer cells achieve resistance to anoikis by several mechanisms including alternations of integrin repertoire, constitutive activation of pro-survival and proliferative signaling, epithelial mesenchymal transition (EMT) and metabolic reprogramming (Kim et al., 2012; Paoli et al., 2013). These events are mediated by the activation of different intracellular signaling networks, which in turn lead to anoikis resistance (Paoli et al., 2013). Following ECM detachment, the hyperactivation of receptor tyrosine kinase growth factor receptors, changes in integrin expression pattern and down-regulation of PTEN result in the activation of pro-survival phosphoinositide 3-kinase (PI3K)/AKT signaling systems. This subsequently inhibits apoptotic process, while deregulation of E-cadherins during EMT elicits the migration of $\beta$-integrin to the nucleus, where it stimulates expression of target genes responsible for cell motility and invasion (Paoli et al., 2013). Tumor cells reprogram metabolic pathways by oxidizing glucose 
via anaerobic glycolysis known as Warburg effect. This Wurburg effect is regulated via activation of PI3K/Akt signaling cascade, hypoxia-inducible factor-1(HIF-1), p53 and AMP-activated protein kinase (AMPK)-liver kinase B-1 (LKB-1) pathways (Kim et al., 2012; Buchheit et al., 2014). Although, various signaling pathways underlying anoikis resistance have been reported, mechanistic players which serve as therapeutic targets for cancer metastasis are still very limited.

Breast cancer cell lines, the estrogen receptorpositive $\left(\mathrm{ER}^{+}\right)$non-metastatic $\mathrm{MCF}-7$ and $\mathrm{ER}^{-}$metastatic MDA-MB-231 breast cancer cell lines have been wellcharacterized for their aggressiveness by both in vitro and in vivo assays (Thompson et al., 1992; Culty et al., 1994; Holliday and Speirs, 2011). Several studies have demonstrated that the malignant phenotypes in the two cell lines are associated with different molecular characters (Eckert et al., 2004; Akekawatchai et al., 2005; Holliday and Speirs, 2011; Niu et al., 2013; Hooshmand et al., 2014). Particularly, identification of biomarkers for tumorigenesis and invasiveness of breast cancer has been studied in these two cell lines (Nagaraja et al., 2006; Lai et al., 2010). In order to explore protein expression profiles responsible for the establishment of anoikis resistance in breast cancer cells, the anchorage-independent survival of these two cell lines was the subject of this study. A comparative proteomic analysis was then conducted to identify protein candidates that are required for anti-anoikis property of breast cancer cells. The proteins as well as their predicted function found in this study provided more evidence to understand the molecular mechanisms involved in anoikis resistance of the metastatic cancer cells.

\section{Materials and Methods}

\section{Cell lines and maintenance}

The non-metastatic breast cancer $\mathrm{MCF}-7$ and metastatic MDA-MB-231 cell lines (obtained from the American Type Culture Collection) were kindly provided by Professor Shaun R. McColl (The University of Adelaide, South Australia) (Akekawatchai et al., 2005; Niu et al., 2013). The two cell lines were cultured in Roswell Park Memorial Institute-1640 (RPMI-1640) medium (GibcoBRL, NY) supplemented with $10 \%$ (v/v) fetal bovine serum (GibcoBRL, NY), $10 \mathrm{mM}$ HEPES, 100 units penicillin and $100 \mathrm{ug} / \mathrm{ml}$ streptomycin, at $37^{\circ} \mathrm{C}$ in a $5 \% \mathrm{CO}_{2}$ atmosphere.

Anchorage-independent culture of MCF-7 and MDAMB-231 cell lines, and treatments

Anchorage-independent cell growth was performed by culturing the cells on anti-adhesive polymer, poly-2hydroxyethyl methacrylate (polyHEMA)-coated 6-well plates containing RPMI-1640 medium supplemented with $10 \%$ FBS. Briefly, culture plates were prepared by adding $0.5 \mathrm{ml}$ of $5 \mathrm{mg} / \mathrm{ml}$ polyHEMA (Sigma-Aldrich) in $95 \%$ ethanol into 6-well plates and dried for 2 days with lids in place followed by extensive washes with PBS (Fukazawa and Uehara, 2000). Cells were seeded at a density of $5 \times 10^{5}$ per well and cultured in RPMI-1640 medium supplemented with 10\% FBS for 24, 48 and 96 hours. At specific time points, the adherent cells were trypsinized and suspended in medium whereas the detached cells were collected. The cell suspension was then subjected to assess viability by trypan blue exclusion assay and cell death by the annexin $\mathrm{V}$ and dead cell assay.

To determine an involvement of phospholipase activity in survival of suspended cells, the cells were cultured in the medium supplemented with various concentrations of specific inhibitors of phospholipase C (PLC), U-73122 (Santa Cruz Bitotechnology, CA), or phospholipase D (PLD), 4-Fluoro-N-(2-(4-(5-fluoro-1H-indol-1-yl) piperidin-1-yl) ethyl) benzamide, 5-Fluoro-2-indolyl des-chlorohalopemide (FIPI) hydrochloride hydrate (FIPI) (Sigma Aldrich) compared with control cultures supplemented with dimethyl sulfoxide (DMSO) and DMSO:methanol (MeOH), respectively for 24 hours and then subjected to the annexin $\mathrm{V}$ and dead cell analysis. A percentage change of apoptotic cells in inhibitor treated cultures were calculated relative to that in control cultures.

Detection of cell viability by trypan blue exclusion assay

The cell suspension was stained with $0.4 \%$ trypan blue in PBS (ratio of 1:1) for 5 minutes before examined under a microscope. A viable cell incapable of excluding the dye shows blue stain while a non-viable cell shows a clear cytoplasm. The percentage of viable cells in anchorage-independent culture was determined in relative to adherent culture.

Cell death analysis by the annexin $V$ and dead cell assay The cell suspension was analyzed by a Muse ${ }^{\mathrm{TM}}$ Annexin V and Dead Cell kit (Merk Millipore Co.,Darmstadt, Germany) according to the manufacturer's protocol. Briefly, the cells were washed twice in ice-cold phosphate buffer saline (PBS) and resuspended at a concentration of $5 \times 10^{5}$ cells $/ \mathrm{ml}$ in $100 \mu \mathrm{l}$ binding buffer $(10 \mathrm{mM}$ HEPES/ $\mathrm{NaOH}$ (pH 7.4), $140 \mathrm{mM} \mathrm{NaCl}, 2.5 \mathrm{mM} \mathrm{CaCl}_{2}$ ). The cells were then incubated with $100 \mu \mathrm{l}$ of the Muse ${ }^{\mathrm{TM}}$ Annexin V and Dead Cell reagent (7-aminoactinomycin D; 7-AAD) at room temperature for 20 minutes in the dark before subjected to a Muse ${ }^{\mathrm{TM}}$ cell analyzer. The survival cells was determined as the percentage of annexin $\mathrm{V}^{-} / 7-\mathrm{AAD}^{-}$cells whereas that of apoptotic cells included the percentages of early (annexin $\mathrm{V}^{+} / 7-\mathrm{AAD}^{-}$) and late apoptotic (annexin $\left.\mathrm{V}^{+} / 7-\mathrm{AAD}^{+}\right)$cells.

\section{Protein extraction for GeLC-MS/MS}

The cultured cells at 24 hours were harvested for protein extraction. The adherent cells were scraped into 2 $\mathrm{ml}$ of cold PBS whereas suspended cells were collected. Cells were centrifuged at 3,000 rpm for 5 minutes, and the pellet was washed once in $1 \mathrm{ml}$ of PBS. The cell pellet was stored at $-80^{\circ} \mathrm{C}$ until use. Subsequently, the frozen cells were thawed and centrifuged at 9,200 $\mathrm{x}$ g for 10 minutes, and the pellet was resuspended in $0.5 \%(\mathrm{w} / \mathrm{v})$ sodium dodecylsulfate (SDS) in water. Protein concentration was measured by Lowrys' method and $50 \mu \mathrm{g}$ of protein samples were subjected to $12.5 \%$ SDS-polyacrylamide gel before staining with colloidal Coomassie blue G. Each lane was sliced in to $1 \times 1 \times 1 \mathrm{~mm}^{3}$ sized gel plugs. 
A

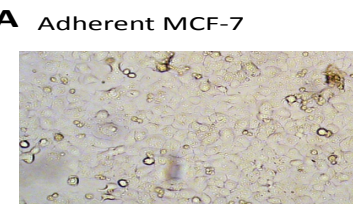

Adherent MDA-MB-231

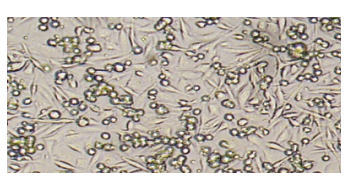

C

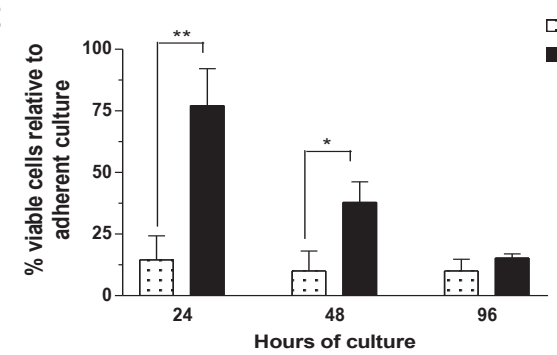

B

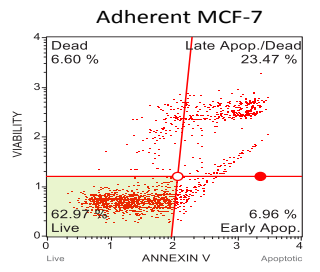

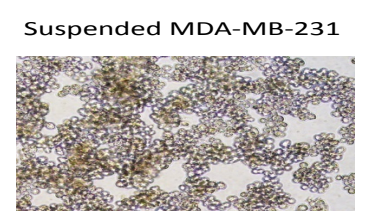

C... MCF-7

MDA-MB-231

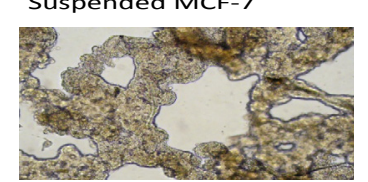

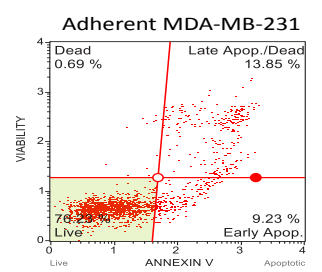

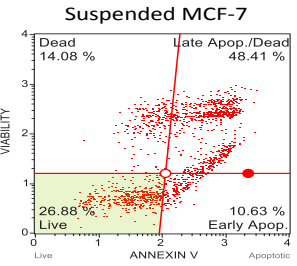

Suspended MDA-MB-231

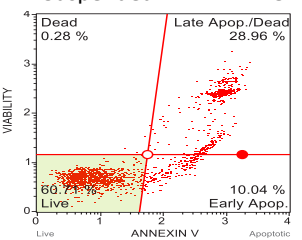

D

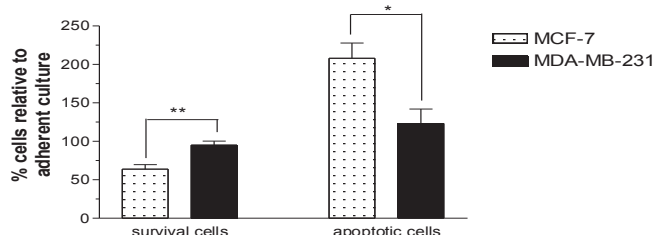

Figure 1. A higher degree of anti-apoptotic ability of MDA-MB-231 than that of MCF-7 cells in the anchorageindependent culture. The survival of cells grown under adherent and anchorage-independent conditions was examined A, representative photographs showing morphologies of the suspended and adherent MCF-7 and MDA-MB-231 cells cultured for 48 hours (x 100). The viability of cells cultured for 24,48 and 94 hours was analyzed by typan blue inclusion assay (C) and the survival of cells cultured at 24 hour cell cultures was also determined by flow cytometry of annexin V-7-AAD double stained cells (B and D). Data are presented as the mean \pm S.E.M of $\%$ cells relative to adherent culture; $n=5$ (C) and $n=4-5$ (D) experiments each performed in duplicate. Asterisks indicate statistical difference between the percentages of viable or apoptotic MCF-7 and MDA-MB-231cells (Student's unpaired $\mathrm{t}$ test) where *, $p<0.05$ and ${ }^{* *}, p<0.005$

\section{A}

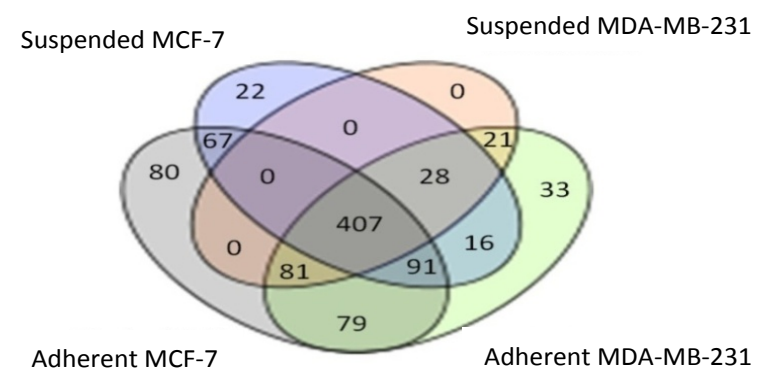

Figure 2. Venn diagram and heatmap analysis of proteins differentially expressed in anchorageindependent MCF-7 and MDA-MB-231 compared with the adherent cells. The extracts of suspended and adherent cells cultured for 24 hours were subject to GeLCMS-MS analysis. A and B show the diagrams of 925 proteins differentially expressed in suspended MCF-7 and MDA-MB-231 cells compared with the adherent cells. A, numbers of proteins expressed in suspended or adherent MCF-7 and MDA-MB-231 cells are shown. B, column 1 and 2 represent protein expression in adherent and suspended MCF-7 whereas column 3 and 4 represent that in adherent and suspended MDA-MB-231 cells respectively. Green, black and red colors represent proteins with low, average and high levels of expression respectively

\section{In-gel digestion}

The gel plugs were placed in 96 well-plate and washed with $200 \mu \mathrm{l} /$ well of sterile distilled water. The plate was shaken for 5 minutes at room temperature and the gel plugs were destained with $25 \mathrm{mM}$ ammonium bicarbonate $\left(\mathrm{NH}_{4} \mathrm{HCO}_{3}\right)$ in $50 \%$ methanol until they become transparent. After the removal of destaining
B

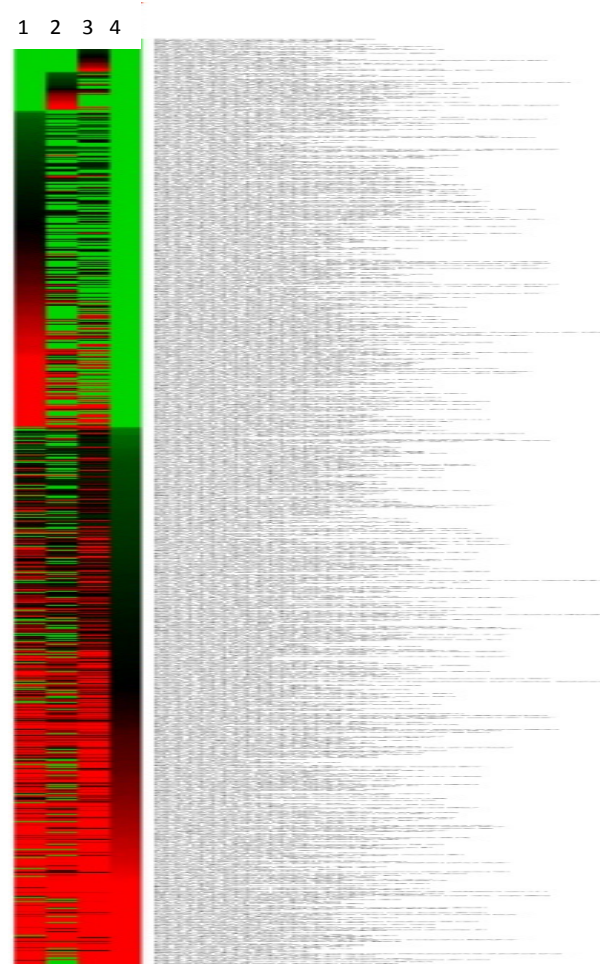

solution and three washes with sterile distilled water, samples were dehydrated with $100 \%$ acetonitrite $(\mathrm{ACN})$, reduced with $10 \mathrm{mM}$ dithiothreitol (DTT) in $10 \mathrm{mM}$ $\mathrm{NH}_{4} \mathrm{HCO}_{3}$ at room temperature for 1 hour and alkylated with $100 \mathrm{mM}$ iodoacetamide (IAA) in $10 \mathrm{mM} \mathrm{NH}_{4} \mathrm{HCO}_{3}$ at room temperature for 1 hour in the dark. The gel slices were then washed twice with $100 \% \mathrm{ACN}$ for 5 minutes. 
Chareeporn Akekawatchai et al

Table 1. A list of 21 proteins expressed in suspended and adherent MDA-MB-231, but not in MCF-7 cells

\begin{tabular}{|c|c|c|c|c|c|}
\hline Database & Protein name & $\begin{array}{l}\text { Protein } \\
\text { ID score }\end{array}$ & Peptides & Biological process & $\begin{array}{l}\text { Subcellular } \\
\text { distribution }\end{array}$ \\
\hline \multicolumn{6}{|l|}{ ID no. } \\
\hline gil386730457 & cib gene product & 15.56 & AADMLAEYERR & cytoskeleton & membrane \\
\hline gil24417711 & nesprin-2 & 16.31 & KAQDLTSLLK & cytoskeleton & $\begin{array}{l}\text { Membrane/ } \\
\text { cytoskeleton }\end{array}$ \\
\hline gil323498894 & 4-alpha-glucanotransferase & 17.65 & KFENAAVQK & Metabolism & cytoplasm \\
\hline gil7662018 & PHD finger protein 3 & 28.98 & KIVAAK & Transcription & nucleus \\
\hline gil42490753 & $\begin{array}{l}\text { transcriptional enhancer } \\
\text { factor TEF-5 }\end{array}$ & 10.18 & TIASSRLR & Transcription & nucleus \\
\hline gil56204959 & $\begin{array}{c}\text { cleavage and } \\
\text { polyadenylation specific } \\
\text { factor 3-like }\end{array}$ & 10.46 & IAVDK & Transcription & cytoplasm \\
\hline gil323302928 & Tuf1p & 16.13 & LLTRTAFKAXGKLLR & Translation & Cytoplasm \\
\hline gil188591432 & transposase, IS6 family & 23.28 & TPRTAPEQVQR & $\begin{array}{l}\text { Epigenic } \\
\text { transcription/ } \\
\text { transposition }\end{array}$ & nucleus \\
\hline gil334117440 & glycosyltransferase family 2 & 12.32 & AFKEDLSMALLR & $\begin{array}{c}\text { Protein } \\
\text { modification }\end{array}$ & Golgi/ER \\
\hline gil330808175 & Phospholipase & 12.92 & LGLSLSDDMR & Signal transduction & cytoplasm \\
\hline gil337729402 & phage related protein & 0.2 & INMADK & Signal transduction & cytoplasm \\
\hline gil51094943 & Piccolo protein (Aczonin) & 7.1 & RDSSSSSLRLK & Signal transduction & $\begin{array}{l}\text { membrane/ } \\
\text { cell junction }\end{array}$ \\
\hline gil52317138 & olfactory receptor $5 \mathrm{R} 1$ & 12.93 & MMVNFVVER & Signal transduction & membrane \\
\hline gil386019860 & acrB gene product & 10.52 & KMPKRTDIK & Signal transduction & membrane \\
\hline gil57167934 & $\begin{array}{c}\text { amino acid } \mathrm{ABC} \text { transporter, } \\
\text { ATP-binding protein }\end{array}$ & 10.32 & IFFMNK & Transport & membrane \\
\hline gil126362955 & $\begin{array}{l}\text { sodium channel protein type } \\
3 \text { subunit alpha isoform } 3\end{array}$ & 6.83 & NSNGTTTETEVRK & Transport & membrane \\
\hline gil157388921 & $\begin{array}{l}\text { transmembrane and coiled- } \\
\text { coil domain-containing } \\
\text { protein } 3 \text { precursor }\end{array}$ & 19.65 & AAITR & Transport & membrane \\
\hline gil333929654 & $\begin{array}{c}\text { outer membrane } \\
\text { autotransporter barrel } \\
\text { domain-containing protein } \\
\end{array}$ & 23.13 & ASAEVAVNK & Transport & membrane \\
\hline gil300869897 & carB gene product & 12.14 & VADVASVGLGRAPR & Stress response & mitochondria \\
\hline gil14133207 & KIAA0556 protein & 8.54 & PEPPPLGMDGQTLR & Unknown & unknown \\
\hline gil327249992 & $\begin{array}{l}\text { phage tail fibre repeat family } \\
\text { protein }\end{array}$ & 14.93 & GRALLAHDTAEAMR & Unknown & unknown \\
\hline
\end{tabular}

In-gel digestion was performed by adding $10 \mathrm{ng} / \mathrm{ml}$ trypsin in $50 \% \mathrm{ACN} / 10 \mathrm{mM} \mathrm{NH}_{4} \mathrm{HCO}_{3}$ to the gels and incubated at room temperature for 20 minutes. The gels were kept immersed throughout the digestion by adding $30 \% \mathrm{ACN}$ before further incubated at $37^{\circ} \mathrm{C}$ overnight. To extract the digested peptides, $50 \%$ ACN in $0.1 \%$ formic acid (FA) was added into the gels and incubated for 10 minutes in a shaker. The peptide products were collected, vacuum dried and stored at $-80^{\circ} \mathrm{C}$ for further mass spectrometric analysis.

\section{$L C-M S / M S$}

The tryptic peptides were analyzed using a HCTultra PTM Discovery System (BrukerDaltonics Ltd, U.K./ Germany) coupled to an UltiMate 3000 LC System (Dionex

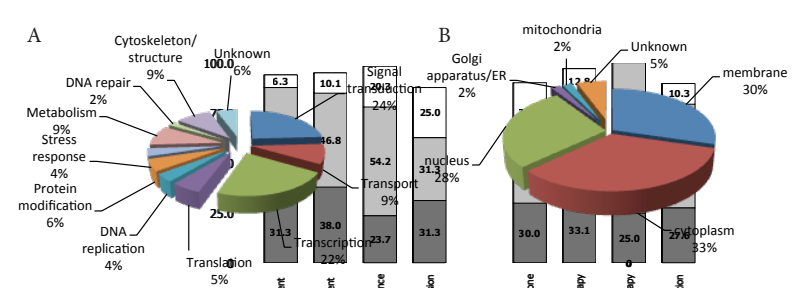

Figure 3. Subcellular distribution and functional annotation of proteins expressed in adherent and suspended MDA-MB-231 cells. Subcellular localization (A) and function (B) of 54 proteins expressed in adherent and suspended MDA-MB-231, but not MCF-7 cells, were obtained from the online Gene Ontology (Go) cat, Uniprot and STITCH 4.0 databases. 
Ltd., U.K./USA). The peptide samples dissolved in $0.1 \%$ FA were separated on a nanocolumn (Onyx monolithic HDC18, $0.2 \mathrm{~mm}$ i.d.6150 mm) with electrospray at a flow rate of $300 \mathrm{nl} / \mathrm{min}$. Mobile phase A was $0.1 \%$ FA and mobile phase B was $80 \%$ ACN with $0.1 \%$ FA. To elute peptides, a multistep gradient was used, starting with an increase from $10 \%-70 \% \mathrm{~B}$ for 13 minutes, $90 \% \mathrm{~B}$ at $13-$ 15 minutes and a decrease to $10 \% \mathrm{~B}$ for $15-20$ minutes. Peptide fragment mass spectra were acquired in data dependent AutoMS mode with a scan range of 30021500

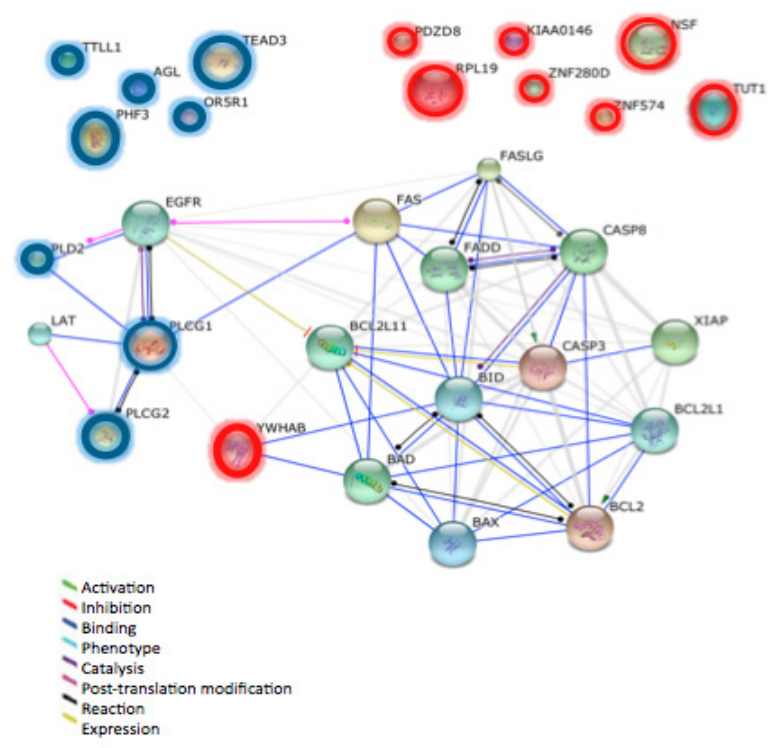

Figure 4. The involvement of 54 candidate proteins in the intrinsic and extrinsic apoptotic signaling pathways predicted by STITCH. Based on the online STITCH 4.0 database, an association of 54 candidate proteins expressed in suspended and adherent MDA-MB-231, but not in MCF-7 cells with FAS, BAX, BCL2 and caspases was predicted with the limiting to Homo sapiens, medium confidence score and no more than 10 interactors. Modes of action are shown in different color lines. Circles indicate identified proteins in this study. The blue and red circles indicate the proteins remained expressed and down-expressed in response to attachment prevention in MDA-MB-231 cells respectively. Abbreviations: domain family member (TEAD3), zinc finger protein 574 (ZNF574), tubulin tyrosine ligase-like family, member 1 (TTLL1), PHD finger protein 3 (PHF3), amylo-1, 6-glucosidase, 4-alphaglucanotransferase (AGL), DNA repair-scaffolding protein KIAA0146 (KIAA0146), olfactory receptor, family 5 , subfamily $\mathrm{R}$, member 1 (OR5R1), PDZ domain containing 8(PDZD8), zinc finger protein $280 \mathrm{D}$ (ZNF280D), terminal uridylyl transferase 1 (TUT1), N-ethylmaleimide-sensitive factor (NSF), ribosomal protein L19 (RPL19), TNF receptor superfamily, member 6 (FAS), Fas ligand (FASLG), Fas-associated via death domain (FADD), caspase 8 (CASP8), BH3 interacting domain death agonist (BID), B-cell lymphoma 2 (BCL2), BCL2-associated agonist of cell death (BAD), BCL2-like 11 (BCL2L11), Bcl-2associated X protein (BAX), BCL2-like 1, (BCL2L1), caspase 3 (CASP3), X-linked inhibitor of apoptosis (XIAP), epidermal growth factor receptor (EGFR), linker activation of $\mathrm{T}$ cells (LAT), phospholipase C gamma 1 (PLCG1), phospholipase C gamma 2 (PLCG2), phospholipase D2 (PLD2) and tyrosine 3-monooxygenase/tryptophan 5-monooxygenase activation protein, 14-3-3 alpha/beta proteins (YWHAB) $\mathrm{m} / \mathrm{z}, 3$ averages, and up to 5 precursor ions selected from the MS scan $5023000 \mathrm{~m} / \mathrm{z}$.

\section{Protein quantitation and identification}

Protein quantitation was performed with DeCyder MS Differential Analysis software (DeCyderMS, GE Healthcare). The acquired LC-MS data were converted and the PepDetect module was used for automate peptide detection, charge state assignments and quantitation based on the peptide ions signal intensities in MS module. The analysed MS/MS data were then submitted for database search using the Mascot software (Matrix Science, London, UK). The data were searched against the NCBI database for protein identification. Search parameters were taxonomy (human), enzyme (trypsin), variable modifications (carbamidomethyl, oxidation of methionine residues), mass values (monoisotonic), protein mass (unrestricted), peptide mass tolerance (1.2 Da), fragment mass tolerance $(60.6 \mathrm{Da})$, peptide charge state $(1+, 2+$ and $3+)$ and mass missed cleavages. Proteins considered as identified proteins had at least one peptide with an individual mascot score corresponding to $p<0.05$. The subcellular localization and molecular function were assigned to protein identification according to the Gene Ontology (Go) cat (http://eagl.unige.ch/GOCat/), Uniprot
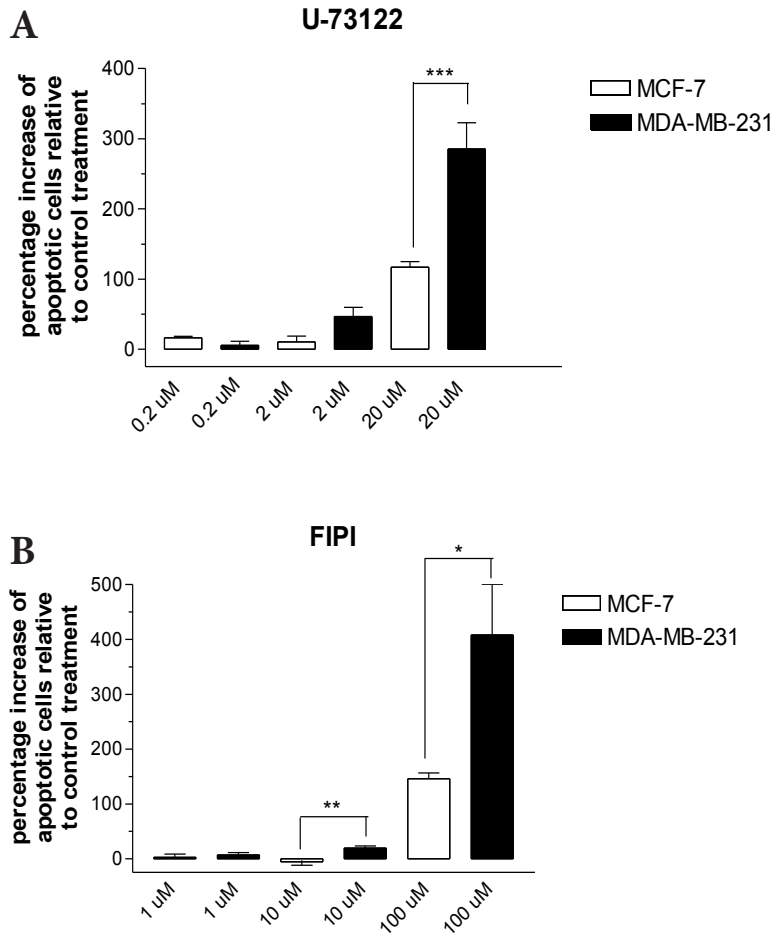

Figure 5. Effects of PLC and PLD Inhibitors on Anchorage-independent growth of MDA-MB-231 and MCF-7 Cells. The suspended cells were incubated with various concentrations of specific inhibitors of PLC, U-73122, and PLD, FIPI, for 24 hours and subjected to cell death analysis. Percentage changes of apototic cells in U-73122 and FIPI (A and $\mathrm{B}$ respectively) treated- relative to control cultures of MCF-7 and MDA-MB-231 cells are shown. Data are presented as the mean \pm S.E.M; $n=3-4$ experiments each performed in duplicate. Asterisks indicate statistical difference between the percentage increase of apoptotic MCF-7 and MDA-MB-231 cells (Student's unpaired $t$ test) where $*, p<0.05$ and ${ }^{* *}, p<0.005, * * * p<0.0001$ 
(http://uniprot.org), STITCH 4.0 (http://stitch.embl. $\mathrm{de} /$ ) databases. Protein-protein interaction was analyzed according to STITCH 4.0 database (http://stitch .embl.de/).

\section{Statistic analysis}

Data were analyzed by unpaired student's t-test using Graphpad Prism Software (San Diego, CA, USA). In all analyses, $p$ values less than 0.05 were considered statistically significant.

\section{Results}

MDA-MB-231 cells grown under an anchorageindependent condition show anoikis property higher than MCF-7 cells.

The ability of MDA-MB-231 and MCF-7 cells to grow in an anchorage-independent condition was initially compared. As shown in Figure 1, attachment prevention of the two cell lines altered their morphologies observed under a microscope. Although MCF-7 cells formed a large cluster of spheroid cells within 24 hours (Data not shown), the poorly formed aggregates of dead or dying cells were observed in 48 hours later (Figure 1A). In contrast, MDAMB-231 cells rapidly formed multicellular spheroids which were more sustainable as shown in Figure 1A. Trypan blue exclusion assay showed that the percentage of viable MCF-7 cells was dramatically decreased within 24 hours of culture whereas that of MDA-MB-21 cells was gradually decreased. The significantly higher percentages of viable MDA-MB-231 cells were observed in 24 and 48 hours of the culture (Figure 1C). Flow cytometric analysis of annexin V-7-AAD double stained cells at 24 hours of culture shown in Figure 1B and 1D demonstrated attachment prevention-induced apoptosis in the two cell lines and a 1.7 fold lower percentage of apoptotic cells relative to adherent culture in MDA-MB-231 than that in MCF-7 cell cultures. These data suggested a significant higher degree of anchorage-independent survival ability of MDA-MB-231 cells.

Protein profiles of MDA-MB-231 and MCF-7 cells grown under anchorage-independent and adherent conditions analyzed by GeLC-MS/MS

In order to explore protein expression profiles involving in the anoikis resistance property of MDAMB-231 breast cancer cells, the suspended and adherent cells cultured at 24 hours was analyzed by GeLC-MS/ MS due to the highest degree of difference between the viability of MDA-MB-231 and MCF-7 cells. A two-way hierarchical clustering analysis shown in Figure 2B indicated that 925 proteins were differentially expressed in the two cell lines grown under suspended or adherent conditions. A Venn diagram showed numbers of proteins that were expressed in the two culture conditions of MCF7 and MDA-MB-231 cells (Figure 2A). Of particular, there were 54 proteins which were expressed only in MDA-MB-231, but not in MCF-7 cells, 33 proteins were found only in the adherent cells whereas 21 proteins remained expressed in the detached cells. Thus, further analysis for their subcellular distribution and functional annotation was performed by the Gene Ontology (Go) cat, Uniprot and STITCH 4.0 as shown in Figure $3 \mathrm{~A}$

Table 2. A list of 33 Proteins Expressed in Adherent MDA-MB-231, but not in MCF-7 cells, and Down-regulated in Detached MDA-MB-231 Cells

\begin{tabular}{|c|c|c|c|c|c|}
\hline $\begin{array}{l}\text { Database } \\
\text { ID no. }\end{array}$ & Protein name & $\begin{array}{l}\text { Protein } \\
\text { ID score }\end{array}$ & Peptides & $\begin{array}{l}\text { Biological } \\
\text { process }\end{array}$ & $\begin{array}{l}\text { Subcellular } \\
\text { distribution }\end{array}$ \\
\hline gil18088719 & beta-tubulin & 59.84 & ISVYYNEATGGK & cytoskeleton & cytoplasm \\
\hline gil29789403 & $\begin{array}{l}\text { PDZ domain-containing } \\
\text { protein } 8\end{array}$ & 21.7 & EGGLDDSVFIAVK & cytoskeleton & cytoplasm \\
\hline gil4758178 & $\begin{array}{l}\text { cytoplasmic dynein } 1 \\
\text { intermediate chain } 1 \text { isoform a }\end{array}$ & 12.35 & SHRRTPVQR & $\begin{array}{l}\text { cytoskeleton, } \\
\text { cell movement, } \\
\text { migration }\end{array}$ & cytoplasm \\
\hline gil119596348 & junctophilin 2, isoform CRA_c & 2.21 & RAAMGR & cytoskeleton & membrane \\
\hline gil21245106 & lipase member $\mathrm{H}$ precursor & 8.87 & VAMVLK & $\begin{array}{l}\text { lipid metabo- } \\
\text { lism }\end{array}$ & membrane \\
\hline gil2906146 & $\begin{array}{l}\text { malate dehydrogenase } \\
\text { precursor }\end{array}$ & 36.51 & AGAGSATLSMAYAGAR & metabolism & $\begin{array}{l}\text { cytoplasms/ } \\
\text { mitochondria }\end{array}$ \\
\hline gil321313747 & dihydropteroate synthase & 8.22 & QIARMAKMMDAMLNK & metabolism & cytoplasm \\
\hline gil301017356 & $\begin{array}{c}\text { glycosyltransferase, group } 1 \\
\text { family }\end{array}$ & 12.48 & TINLSSERK & metabolism & membrane \\
\hline gil297620850 & vesicle-fusing ATPase & 14.82 & GGSVNK & Transport & Cytoplasm \\
\hline gil329938632 & DNA gyrase subunit A & 5.21 & VGGIADVR & $\begin{array}{l}\text { DNA replica- } \\
\text { tion }\end{array}$ & nucleus \\
\hline gil320178239 & ATP-dependent helicase hrpA & 11.31 & KGRSGR & $\begin{array}{l}\text { DNA replica- } \\
\text { tion }\end{array}$ & Neucleus \\
\hline gil76496497 & protein artemis isoform a & 10.7 & GLRAPTLKRR & DNA repair & Nucleus \\
\hline gil116052873 & cbrB gene product & 5.56 & SGASADS & Transcription & nucleus \\
\hline
\end{tabular}




\begin{tabular}{|c|c|c|c|c|c|}
\hline $\begin{array}{l}\text { Database } \\
\text { ID no. }\end{array}$ & Protein name & $\begin{array}{l}\text { Protein } \\
\text { ID score }\end{array}$ & Peptides & $\begin{array}{l}\text { Biological } \\
\text { process }\end{array}$ & $\begin{array}{l}\text { Subcellular } \\
\text { distribution }\end{array}$ \\
\hline gil119597574 & $\begin{array}{c}\text { AT hook containing } \\
\text { transcription factor } 1 \text {, isoform } \\
\text { CRA_d }\end{array}$ & 1.05 & LIRTY & Transcription & Nucleus \\
\hline gil187761317 & $\begin{array}{c}\text { methylcytosinedioxygenase } \\
\text { TET2 isoform a }\end{array}$ & 2.79 & LPPNLSNPNMDYK & Transcription & nucleus \\
\hline gil333985858 & $\begin{array}{l}\text { restriction modification system } \\
\text { DNA specificity domain- } \\
\text { containing protein }\end{array}$ & 22.44 & KRKLVELLK & Transcription & nucleus \\
\hline gil154744870 & zinc finger protein 574 & 13.26 & TFVNLTK & Transcription & Neucleus \\
\hline gil333396626 & transcriptional regulator CtsR & 11.79 & LYDDQVIERK & Transcription & Neucleus \\
\hline gil300253409 & heat shock protein 70-p1 & 19.14 & TTPSYVAFTESER & Transcription & $\begin{array}{l}\text { nucleus/ } \\
\text { cytoplasm }\end{array}$ \\
\hline gil306836586 & $\begin{array}{l}\text { cse } 1 \text { family CRISPR- } \\
\text { associated protein }\end{array}$ & 4.83 & EGVAHA & transcription & Nucleus \\
\hline gil4506609 & 60S ribosomal protein L19 & 9.95 & KGTANAR & Translation & Cytoplasm \\
\hline gil337751588 & $\begin{array}{l}\text { histidinol-phosphate } \\
\text { aminotransferase }\end{array}$ & 11.76 & KNGGPA & Translation & Cytoplasm \\
\hline gil133777378 & NMT1 protein & 7.77 & ALNSS & $\begin{array}{c}\text { Protein } \\
\text { modification }\end{array}$ & Cytoplasm \\
\hline gil300245991 & carboxylyase-like protein & 18.84 & $\begin{array}{l}\text { ESGGAASYLVI- } \\
\text { SIRNYGAAGLAK }\end{array}$ & $\begin{array}{c}\text { Protein } \\
\text { modification }\end{array}$ & $\begin{array}{l}\text { plasma mem- } \\
\text { brane }\end{array}$ \\
\hline gil4504237 & $\begin{array}{l}\text { semaphorin-7A isoform } 1 \\
\text { preproprotein }\end{array}$ & 12.78 & AAPSAPR & $\begin{array}{c}\text { Signal } \\
\text { transduction }\end{array}$ & membrane \\
\hline gil8923394 & $\begin{array}{l}\text { transmembrane protein } 161 \mathrm{~A} \\
\text { isoform } 1 \text { precursor }\end{array}$ & 8.54 & ALAGKPRPR & $\begin{array}{c}\text { Signal } \\
\text { transduction }\end{array}$ & membrane \\
\hline gil386316270 & pyrG gene product & 31.38 & ADMTEWSAMVDK & $\begin{array}{c}\text { Signal } \\
\text { transduction }\end{array}$ & membrane \\
\hline gil 1072378 & PEP-19 & 9.05 & QGAGPTNGKDK & $\begin{array}{c}\text { Signal } \\
\text { transduction }\end{array}$ & $\begin{array}{l}\text { Cytoplasm/ } \\
\text { Neucleus }\end{array}$ \\
\hline gil4507949 & 14-3-3 protein beta/alpha & 34.12 & NLLSVAYK & $\begin{array}{c}\text { Signal } \\
\text { transduction }\end{array}$ & cytoplasm \\
\hline gil307544419 & bchI gene product & 10.76 & IGGVLISGPK & $\begin{array}{c}\text { Signal } \\
\text { transduction }\end{array}$ & Cytoplams \\
\hline gil119623684 & $\begin{array}{l}\text { FLJ45422 protein, isoform } \\
\text { CRA_b }\end{array}$ & 5.11 & MGVMAPR & $\begin{array}{c}\text { Signal } \\
\text { transduction }\end{array}$ & nucleus \\
\hline gil333369681 & cytochrome c, class I & 30.77 & AQKGMPALVESVR & $\begin{array}{c}\text { Signal } \\
\text { transduction }\end{array}$ & cytoplasm \\
\hline gil1469874 & KIAA0146 & 10.99 & TPENSAKKK & Unknown & uncharacterised \\
\hline
\end{tabular}

and $\mathrm{B}$, respectively. These proteins were involved in various cellular processes, including cell signaling (24\%), transcription (22\%), metabolism (9\%), cytoskeleton/ structure $(9 \%)$, transport (9\%), protein modification $(6 \%)$, translation $(5 \%)$, stress response $(4 \%)$, DNA replication and repair (4\%) and unknown function (6\%) and they were located in cytoplasm (33\%), membrane $(30 \%)$, nucleus (28\%), golgi apparatus and endoplasmic reticulum (2\%), mitochondria (2\%) and unidentified location (5\%). A full list of 21 proteins which are expressed both in the suspended and adherent MDA-MB-231 cells is shown in Table 1 whereas 33 proteins which were found only in the adherent cells are shown in Table 2. Our data demonstrated the differential protein expression of the two cell lines in response to attachment prevention and there were 54 proteins found in detached and adherent MDA-MB-231, but not in MCF-7, cells that potentially involved in the higher degree of anti-anoikis of the highly metastatic MDA-MB-231 cells.

STITCH analysis for an association of candidate proteins with the apoptotic signaling network in the highly metastatic MDA-MB-231 cells

To identify signal transduction pathways relevant to the anoikis resistance phenotype of the MDA-MB-231 cells, a total of 54 proteins expressed only in the suspended and adherent MDA-MB-231, were analyzed for their interaction with the classical extrinsic and intrinsic apoptotic signaling molecules, TNF receptor superfamily, member 6 (Fas), BCL-2-associated X protein (Bax), 
Chareeporn Akekawatchai et al

B-cell lymphoma 2 (BCL2) and apoptosis-related cysteine peptidases (caspases) according to online STITCH 4.0 database (Kuhn et al., 2014). The analysis was based on the following parameters: species, Homo sapiens; confidence score, medium; active prediction methods, all and using a list of multiple protein names as input. As shown in Figure 4, the 12 candidate proteins including domain family member (TEAD3), zinc finger protein 574 (ZNF574), tubulin tyrosine ligase-like family, member 1 (TTLL1), PHD finger protein 3 (PHF3), amylo-1, 6-glucosidase, 4-alpha-glucanotransferase (AGL), DNA repair-scaffolding protein KIAA0146 (KIAA0146), olfactory receptor, family 5 , subfamily $\mathrm{R}$, member 1 (OR5R1), PDZ domain containing 8 (PDZD8), zinc finger protein 280D (ZNF280D), terminal uridylyl transferase 1 (TUT1), N-ethylmaleimide-sensitive factor (NSF) and ribosomal protein L19 (RPL19) did not show any interaction network with apoptotic pathways. However, the analysis predicted contribution of phospholipases, PLCG1, PLCG2, PLD2 and 14-3-3 beta/alpha, YWHAB, to the apoptotic network. Apparently, the phospholipase isoforms, PLC and PLD, remained expressed in the detached cells (Table 1) and were predicted to be downstream of epidermal growth factor receptor (EGFR) that are negative regulator of the extrinsic Fas-FasL and intrinsic Bax-related signaling pathways. Another protein, 14-3-3 beta/alpha, YWHAB, which is down-regulated in response to cell detachment (Table 2) was found to be associated with BH3 interacting domain death agonist (BID) and BCL2-associated agonist of cell death (BAD). The STITCH analysis suggests that constitutive expression of phospholipase isoenymes, and the down-regulation of 14-3-3 beta/alpha, YWHAB, potentially play roles in the regulation of apoptotic signaling pathways in response to the detachment of MDA-MB-231 cells.

Phospholipases is essential for the anchorage-independent survival of MDA-MB-231 and MCF-7 cells

Previous studies have clearly demonstrated higher expression levels and activity of PLC and PLD isoforms in MDA-MB-231 than those in MCF-7 cells (Zhong et al., 2003; Abalsamo et al., 2012). To validate our proteomics data and determine roles of PLC and PLD activity in supporting anoikis resistant property, both cell lines were grown under an anchorage-independent culture condition in the presence of, U-73122 or FIPI, which are inhibitors of PLC or PLD, respectively (Kumar et al., 2012; Henkels et al., 2013). The percentages of apoptotic cells represented by annexin $\mathrm{V}^{+} / 7-\mathrm{AAD}^{-}$and annexin $\mathrm{V}^{+} / 7-\mathrm{AAD}^{+}$cells were measured. Figure $5 \mathrm{~A}$ and $\mathrm{B}$ show percentage changes of the annexin $\mathrm{V}^{+} / 7-\mathrm{AAD}^{-}$and annexin $\mathrm{V}^{+} / 7-\mathrm{AAD}^{+}$cells in U-73122 and FIPI-treated cultures of MDA-MB-231 and MCF-7 cells relative to their adherent culture conditions. The data indicated that both U-73122 and FIPI treatment increased percent apoptotic cells in a dose-dependent manner in both cell lines. We also observed a higher percentage increase of apoptotic cells in the anchorageindependent culture conditions of specific PLC and PLD inhibitor-treated MDA-MB-231 than that of MCF-7 cells. These data suggest a stronger contribution of PLC and PLD activity in supporting anchorage-independent survival of MDA-MB-231 than MCF-7 cells.

\section{Discussion}

The non-metastatic MCF-7 and metastatic MDAMB-231 breast cancer cell lines have long been widely used in breast cancer research (Holliday and Speirs, 2011). In vitro and in vivo studies have shown considerable differences in the invasive and metastatic abilities (Thompson et al., 1992; Culty et al., 1994). The significant difference in their cellular and molecular characteristics has also been demonstrated in many studies (Eckert et al., 2004; Akekawatchai et al., 2005; Holliday and Speirs, 2011; Niu et al., 2013; Hooshmand et al., 2014). The two cell lines have been shown to be resistant to anoikis (Mahadev et al., 2002; Bharadwaj et al., 2005; Kim et al., 2010). However, the studies demonstrating a comparison of their anchorage-independent survival are still very limited. Our data showed the significantly higher survival ability of MDA-MB-231 than that of MCF-7 cells in response to attachment prevention, which is consistent with the invasive and metastatic abilities (Thompson et al., 1992; Culty et al., 1994). Previous studies also indicated the differential gene expression and proteomic profiles of the two cell lines and identified proteins which can serve as potential markers for tumorigenesis and invasiveness of breast cancer (Nagaraja et al., 2006; Lai et al., 2010). Therefore, the two breast cancer cell lines were used to comparatively analyze putative mediators involving anoikis resistance in response to ECM detachment.

As proteomics is a potential tool widely used in searching for proteins as well as their functionality in different cellular systems (Chesor et al., 2014; Kuhn et al., 2014; Laothumthut et al., 2015), the expression of the two cell lines in response to cell detachment was analyzed by the GeLC-MS/MS technique. Our data revealed that 925 proteins were expressed differentially in suspended or adherent cultures of MCF-7 and MDA-MB-231 cells, indicating their involvement in the attachment prevention. Of particular, 54 out of 925 proteins found only in the detached and adherent MDA-MB-231 cells, of which 33 proteins are down-regulated whereas 21 proteins remained expressed in response to the attachment prevention. These proteins were identified to be associated with various functions including cytoskeleton/structure, cell metabolisms, DNA replication and repair, transcription and translation, protein modification, cell signaling, transport and stress response, all of which potentially support ability of the cell to resist anoikis.

Previous studies indicated that cancer cells may employ different strategies to counteract the apoptotic pathways in response to the detachment from ECM, leading to anchorage-independent growth (Paoli et al., 2013). Thus, an association of the proteins identified in this study with the classical apoptotic signaling pathways was examined by STITCH 4.0. This demonstrates that there was no interaction of the 12 candidate proteins including the remaining expressed proteins, TTLL1, AGL, PHF3, TEAD3, OR5R1, and the down-expressed proteins, ZNF574, TUT1, KIAA0146, PDZD8,ZNF280D, NSF and RPL19 to the apoptotic signaling network in 
MDA-MB-231 cells. There are possible explanations for the findings. Some of these proteins have not been well-characterized and, therefore, no data available in the database. Additionally, although these proteins may have no direct association with anoikis ability of the cells, their involvement in other activities supporting the anchorage-independent survival could not be ruled out. In contrast, our data indicated the interaction of phospholipase isoenymes, PLC and PLD, which remained expressed in MDA-MB-231 cells, and 14-3-3 beta/alpha, YWHAB, which was down-expressed in response to detachment of the cells, with the intrinsic and extrinsic apoptotic signaling network. Whereas the expression of phospholipases potentially participate in the downregulation of apoptotic signal transduction supporting the cells to overcome anoikis in response to the attachment prevention, the down-regulation of the 14-3-3 beta/alpha may support a certain degree of apoptotic cell death observed in the MDA-MB-231 cells. It is a very first time to specifically implicate these signaling proteins in anoikis resistance of the highly metastatic MDA-MB-231 cells.

Several previous studies have characterized expression and function of PLC and PLD isoenzymes in MCF-7 and MDA-MB-231 cells (Zhong et al., 2003; Abalsamo et al., 2012). Our proteomics analysis demonstrated that there was a constitutive expression of phospholipases observed only in MDA-MB-231, but not in MCF-7 cells and remained expressed in response to the attachment prevention. Inhibitor experiments also suggested the involvement of PLC and PLD in anoikis resistance of the two cell lines and a stronger contribution of PLC and PLD activity in anti-anoikis of MDA-MB-231 than those in MCF-7 cells. These data are consistent with several previous studies demonstrating the higher expression levels and activity of different phospholipase isoforms including phosphatidylcholine-PLC (PC-PLC) and PLD in MDA-MB-231 than those in MCF-7 cells. The activities of these isoenzymes were apparently essential for maintaining the mesenchymal-like phenotype, antiapoptosis induced by serum withdrawal and, migration and invasion of the cells (Zhong et al., 2003; Zheng et al., 2006; Abalsamo et al., 2012).

Generally, PLC and PLD are phospholipid-hydrolyzing isoenzymes which can generate many intracellular bioactive lipid mediators which in turn regulate various cellular processes, leading to tumorigenesis, migration and invasion (Park et al., 2012). Both isoenzymes can be activated in response to the stimulation of mitogenic signals including epidermal growth factors (EGF) through their respective receptor tyrosine kinase EGFRs (Roskoski, 2014). It appears that the interaction of SH-2 domain of phospholipase C gamma (PLCG) with the phosphotyrosine residues on the activated RTKs can activate PLCG-mediated proliferative signaling via the protein kinase B-induced gene expression (Park et al., 2012; Roskoski, 2014). The growth factor signaling also increases the activity of phospholipase D (PLD) isoenzymes that generate phosphatidic acid and recruit RAF to plasma membrane to activate the mitogen-activated protein kinase (MAPK) signaling pathway (Rizzo et al., 1999). In this study, analysis based on STITCH database predicted that PLC and PLD are potentially downstream of epidermal growth factor receptor (EGFR) that are negative regulator of the extrinsic Fas-FasL and intrinsic Bax-related signaling pathways (Figure 4), consistent with the evidence demonstrating the EGFR expression and activity of Fas-FasL-mediated apoptotic signaling in the MDA-MB-21 cells (Pledgie-Tracy et al., 2007; Cui et al., 2013). Thus, it is highly possible that the metastatic MDAMB-231 cells utilize growth factor signaling through PLC and PLD to counteract the apoptotic signaling pathways in response to the ECM detachment. While accumulating studies indicated that the PI3K signaling system plays a central role in anti-anokis of a cell (Park et al., 2012), our data have shown a potential involvement of the phospholipase-dependent signaling system in overcoming anoikis of this cell type.

In conclusion, this study has demonstrated the significantly higher degree of anchorage-independent survival in the metastatic MDA-MB-231 than that in non-metastatic MCF-7 cells. The comparative proteomic analysis indicated the differential protein expression profiles in the two cell lines in response to attachment prevention. In particular, there were 54 identified proteins expressed only in adherent and detached MDA-MB-231, but not in MCF-7 cells, that potentially contribute to the high level of anti-apoptotic ability of the MDA-MB-231 cells. Analysis of these identified proteins according to STITCH database together with the functional experiments suggested that this cell type potentially exploits the growth factor signaling through phospholipases, PLC or PLD, to counteract the apoptotic process induced in response to the ECM detachment. In contrast, STITCH analysis indicated that the up-regulation of apoptotic signaling pathways in response to detachment of the cells may be promoted by the down-regulation of 14-3-3 beta/alpha, YWHAB, regulatory protein. These signaling mediators as well as other identified proteins reported in this study require more clarification in terms of their expression and function in the establishment of anoikis resistance of the metastatic breast cancer cells and may serve as biomarkers and therapeutic targets for the advanced breast cancer.

\section{Acknowledgements}

This study was financially supported by Thailand Research Fund (TRF) and Commission on Higher Education (CHE), MRG5280163 and Thammasat University (research fund academic year of 2009). The authors declare that they have no conflict of interest.

\section{References}

Abalsamo L, Spadaro F, Bozzuto G, et al (2012). Inhibition of phosphatidylcholine-specific phospholipase $\mathrm{C}$ results in loss of mesenchymal traits in metastatic breast cancer cells. Breast Cancer Res, 14, 50.

Akekawatchai C, Holland JD, Kochetkova M, et al (2005). Transactivation of CXCR4 by the insulin-like growth factor-1 receptor (IGF-1R) in human MDA-MB-231 breast cancer epithelial cells. J Biol Chem, 280, 39701-8.

Bharadwaj S, Thanawala R, Bon G, et al (2005). Resensitization of breast cancer cells to anoikis by tropomyosin-1: role 
Chareeporn Akekawatchai et al

of Rho kinase-dependent cytoskeleton and adhesion. Oncogene, 24, 8291-303.

Buchheit CL, Weigel KJ, Schafer ZT (2014). Cancer cell survival during detachment from the ECM: multiple barriers to tumour progression. Nat Rev Cancer, 14, 632-41.

Chesor M, Roytrakul S, Graidist P, et al (2014). Proteomics analysis of siRNA-mediated silencing of Wilms' tumor 1 in the MDA-MB-468 breast cancer cell line. Oncol Rep, 31, 1754-60.

Cui W, Zhang S, Shan C, et al (2013). microRNA-133a regulates the cell cycle and proliferation of breast cancer cells by targeting epidermal growth factor receptor through the EGFR/Akt signaling pathway. FEBS J, 280, 3962-74.

Culty M, Shizari M, Thompson EW, et al (1994). Binding and degradation of hyaluronan by human breast cancer cell lines expressing different forms of CD44: correlation with invasive potential. J Cell Physiol, 160, 275-86.

Eckert LB, Repasky GA, Ulku AS, et al (2004). Involvement of Ras activation in human breast cancer cell signaling, invasion, and anoikis. Cancer Res, 64, 4585-92.

Fukazawa H, Uehara Y (2000). U0126 reverses Ki-ras-mediated transformation by blocking both mitogen-activated protein kinase and p70 S6 kinase pathways. Cancer Res, 60, 2104-7.

Glinskii AB, Smith BA, Jiang P, et al (2003). Viable circulating metastatic cells produced in orthotopic but not ectopic prostate cancer models. Cancer Res, 63, 4239-43.

Henkels KM, Boivin GP, Dudley ES, et al (2013). Phospholipase $\mathrm{D}$ (PLD) drives cell invasion, tumor growth and metastasis in a human breast cancer xenograph model. Oncogene, $\mathbf{3 2}$, 5551-62.

Holliday DL, Speirs V (2011). Choosing the right cell line for breast cancer research. Breast Cancer Res, 13, 215.

Hooshmand S, Ghaderi A, Yusoff K, et al (2014). Differentially expressed proteins in ER+ MCF7 and ER- MDA- MB-231 human breast cancer cells by RhoGDI-alpha silencing and overexpression. Asian Pac J Cancer Prev, 15, 3311-7.

Kim JB, Yu JH, Ko E, et al (2010). The alkaloid Berberine inhibits the growth of Anoikis-resistant MCF-7 and MDAMB-231 breast cancer cell lines by inducing cell cycle arrest. Phytomedicine, 17, 436-40.

Kim YN, Koo KH, Sung JY, et al (2012). Anoikis resistance: an essential prerequisite for tumor metastasis. Int J Cell Biol, 2012, 306879.

Kuhn M, Szklarczyk D, Pletscher-Frankild S, et al (2014). STITCH 4: integration of protein-chemical interactions with user data. Nucleic Acids Res, 42, 401-7.

Kumar B, Kumar A, Ghosh S, et al (2012). Diospyrin derivative, an anticancer quinonoid, regulates apoptosis at endoplasmic reticulum as well as mitochondria by modulating cytosolic calcium in human breast carcinoma cells. Biochem Biophys Res Commun, 417, 903-9.

Lai TC, Chou HC, Chen YW, et al (2010). Secretomic and proteomic analysis of potential breast cancer markers by two-dimensional differential gel electrophoresis. J Proteom Res, 9, 1302-22.

Laothumthut T, Jantarat J, Paemanee A, et al (2015). Shotgun proteomics analysis of proliferating STRO-1-positive human dental pulp cell after exposure to nacreous water-soluble matrix. Clin Oral Invest, 19, 261-70.

Mahadev K, Raval G, Bharadwaj S, et al (2002). Suppression of the transformed phenotype of breast cancer by tropomyosin-1 . Exp Cell Res, 279, 40-51.

Malin D, Strekalova E, Petrovic V, et al (2015). ERK-regulated alphaB-crystallin induction by matrix detachment inhibits anoikis and promotes lung metastasis in vivo. Oncogene, 34, 5626-34.

Nagaraja GM, Othman M, Fox BP, et al (2006). Gene expression signatures and biomarkers of noninvasive and invasive breast cancer cells: comprehensive profiles by representational difference analysis, microarrays and proteomics. Oncogene, 25, 2328-38.

Niu M, Klingler-Hoffmann M, Brazzatti JA, et al (2013). Comparative proteomic analysis implicates eEF2 as a novel target of PI3Kgamma in the MDA-MB-231 metastatic breast cancer cell line. Proteome Sci, 11, 4.

Paoli P, Giannoni E, Chiarugi P (2013). Anoikis molecular pathways and its role in cancer progression. Biochim Biophys Acta, 1833, 3481-98.

Park JB, Lee CS, Jang JH, et al (2012). Phospholipase signalling networks in cancer. Nat Rev Cancer, 12, 782-92.

Pledgie-Tracy A, Sobolewski MD, Davidson NE (2007). Sulforaphane induces cell type-specific apoptosis in human breast cancer cell lines. Mol Cancer Ther, 6, 1013-21.

Rizzo MA, Shome K, Vasudevan C, et al (1999). Phospholipase $\mathrm{D}$ and its product, phosphatidic acid, mediate agonistdependent raf-1 translocation to the plasma membrane and the activation of the mitogen-activated protein kinase pathway. J Biol Chem, 274, 1131-9.

Roskoski R, Jr. (2014). The ErbB/HER family of protein-tyrosine kinases and cancer. Pharmacol Res, 79, 34-74.

Thompson EW, Paik S, Brunner N, et al (1992). Association of increased basement membrane invasiveness with absence of estrogen receptor and expression of vimentin in human breast cancer cell lines. J Cell Physiol, 150, 534-44.

Zheng Y, Rodrik V, Toschi A, et al (2006). Phospholipase D couples survival and migration signals in stress response of human cancer cells. J Biol Chem, 281, 15862-8.

Zhong M, Shen Y, Zheng Y, et al (2003). Phospholipase D prevents apoptosis in v-Src-transformed rat fibroblasts and MDA-MB-231 breast cancer cells. Biochem Biophys Res Commun, 302, 615-9. 